\title{
FORMULATION AND DEVELOPMENT OF LENALIDOMIDE LOADED DELAYED RELEASE MINI TABLETS IN CAPSULES
}

\author{
L. SONALI MEHTA, D. V. GOWDA*, N. VISHAL GUPTA, MANOHAR M.
}

Department of Pharmaceutics, JSS College of Pharmacy, Sri Shivarathreeshwara Nagara, Mysuru, JSS Academy of Higher Education and Research, JSS Medical Institutions Campus, Sri Shivarathreeshwara Nagara, Mysuru 570015, Karnataka, India

Email: dvgowda@jssuni.edu.in

Received: 11 Apr 2018, Revised and Accepted: 11 Aug 2018

\section{ABSTRACT}

Objective: Formulation and development of delayed release mini tablets in the capsule of drug lenalidomidein terms of dissolution and stability was the objective of the present work.

Methods: Tablets of less than or equal to 3 millimetres diameter are Mini-tablets, which were filled into a capsule. Direct compression method using multitip punch was used for compression and coated with eudragit L100 as a seal coating material and with eudragit L30D55 as an enteric coating material was done. Different formulations were prepared and subjected for evaluation like weight variation, hardness, friability, disintegration, and dissolution studies. The optimized formulation was compared to marketed product based on drug released profile and also subjected for stability studies.

Results: The results revealed that the in vitro drug release of prepared formulations, F1, F2, F3, and F4 was subjected for acid resistance test for $2 \mathrm{~h}$ in $0.1 \mathrm{~N} \mathrm{HCl}$ and has a comparable dissolution profile in phosphate buffer of $6.8 \mathrm{pH}$. FormulationF4 was subjected for stability studies and no significant difference was observed in $3 \mathrm{mo} 40{ }^{\circ} \mathrm{C} / 75 \% \mathrm{RH}$ accelerated stability condition.

Conclusion: The dissolution profile of formulation F4 was found better than that of market product. Based on evaluation results, the study concluded that F4formulationwas considered as an optimized formulation.

Keywords: Immuno-modulator, Mini-tablets, Delayed-release, Tablets in capsule, Lenalidomine

(C) 2018 The Authors. Published by Innovare Academic Sciences Pvt Ltd. This is an open access article under the CC BY license (http://creativecommons.org/licenses/by/4.0/] DOI: http://dx.doi.org/10.22159/ijap.2018v10i5.26658

\section{INTRODUCTION}

The aim of any dosage form was to release the effective and precise amount of drug at the target site to give a desired pharmacological response. Delayed release system are systems used for repetitive and intermittent dosing of a drug from multiple immediate release units that is merged into a single dosage form [1]. Mini tablets are slightly curved or flat tablets which have diameter ranged between 1.0-3.0 millimeters; they can thus be filled into capsules. Mini tablets can be compressed into larger tablets, and occasional it can be filled in sachets for easy administration [2]. The drug release can be achieved due to increase surface in relationship with volume of drug.

The rationale of mini tablets formulation is to accomplish several releases in one formulation by combining altered dose. Passage of mini tablets through the stomach is better than normal tablets due to their small dimension. Due to this, mini tablets are formulated in the study to achieve the desired drug concentration in plasma is achieved [3].

Formulation of one capsule containing different mini tablets, each developed independently and designed to release at the different site of the gastrointestinal tract can be achieved. Mini tablets have the merit of achieving multi-particulate dosage forms with the conventional manufacturing systems of tableting [4]. A further advantage of mini tablets includes their uniformity in size, shape, and surface, thereby offering an exceptional well substrate for coating with modified release polymeric systems [5].
When the capsule disintegrates, mini-tablets inside the capsule release and distribute throughout the gastrointestinal tract. The subunits act as self-contained depots, which makes it possible for the division of multiple unit tablets with no loss in depot effect. Mini tablets represent total subunits present in the capsules. The therapeutic effect of the capsule is directly related to the functionality of each mini tablet in the capsule [6].

Thalidomide on chemical modification yields lenalidomide. This potent analogue has decreased neurological effects such as sedation and neuropathy as compared to parent molecule. It shows an effect against haematological and solid malignancies. Lenalidomine being immunomodulatory shows the effect on the immune system at both cellular and humoral limbs. It also exhibits anti-angiogenic action. The novelty of the study lies in formulation and development of delayed release mini tablets in the capsule of drug lenalidomide. The drug was chosen with the aim to reduce the side effects of thalidomide and improve the increases the efficacy [7].

\section{MATERIALS AND METHODS}

\section{Materials}

Lenalidomide was obtained as a sample from Sigma Alrich Pvt. Ltd, Mumbai, India, along with triethyl citrate. Microcrystalline cellulose, silicified microcrystalline cellulose, magnesium stereate, and talc was procured from Loba Chemie Pvt. Ltd. croscarmellose sodium, silica colloidal silicon dioxide and type a methacrylic acid copolymer dispersion was procured from Merck Pvt. Ltd.

Table 1: List of equipment and instruments

\begin{tabular}{lll}
\hline S. No. & Name & Manufacturer \\
\hline 1. & Blender & Ganson Engineers Private Limited \\
2. & Tablet Compression machine & Cadmach machine Co. PVT LTD \\
3. & Tablet Coating machine & Gansons Limited \\
4. & Digital weighing balance & Shimadzu \\
5. & Hardness tester & Monsanto \\
6. & Disintegration test apparatus & Electro lab \\
\hline
\end{tabular}




\section{Pre-formulation studies}

\section{Fourier transform infra-red (FT-IR) spectrum}

A Fourier Transform Infrared (FTIR) spectrum was carried out to check the chemical compatibility of Drug and Excipient by Shimadzu 8400S FTIR (Tokyo, Japan) by $\mathrm{KBr}$ pellet press method. The Spectrum was recorded over the range $40-4 \mathrm{~m}^{-1}[8]$.

\section{Preparation procedure}

The preparation was carried out after obtaining all the ingredients. Sifting was done by co-sifting API, Microcrystalline cellulose, Silica colloidal silicon dioxide, and Acdisol, Aerosil, through sieve \#40. The sifted granules were mixed in a blender for $20 \mathrm{~min}$ at 15 rotations per min to achieve uniform blending. The lubrication was done by using Magnesium stearate. Compression of the tablet was done using a double rotatory compression machine using 2 millimeters diameter standard concave plain punch [9]. Seal coating was done by using eudragit L 100 solution.

\section{Preparation of eudragit L100 solution}

Was done by weighing required quantity of eudragit L 100, isopropyl alcohol and triethylcitrate (TEC). In lenalidomide, steadily add triethyl citrate and mixing for 10 min was done. Then eudragit L 100 was added to the above solution. Stirred for one and a half hours until a clear solution was formed $[10,11]$. Then seal coating was carried out on compressed core mini tablets. The enteric coating was done by eudragit L30D55 solution.

\section{Preparation of eudragit L30D55 solution}

Was done by, weighing required quantity of Purified Water, talc, TEC, eudragit L30 D55, in water, TEC was gradually added. Talc was diversified for $15 \mathrm{~min}$ followed by addition of dimethicon. In the above solution Eudragit L30D55 was slowly added, with continuous stirring for thirty minutes. Then enteric coating was performed on seal coated mini tablets $[12,13]$. Capsule filling and Packing was done in the next step; the drug product was intended to be labelled for storage at $15^{\circ}-30^{\circ} \mathrm{C}[14,15]$.

All the other ingredients were kept constant and the concentration of eudragit L30D55 as enteric coating and eudragit L100 as seal coating were changed for different formulations from F1 to F4 (table 2).

\section{Post-compression and coating parameters}

Evaluation of mini tablets was done for parameters like weight variation, hardness, thickness, and disintegration and tabletting issues such as capping, sticking. The mini-tablets were inspected for shape, colour and other tablet defects by keeping the tablets in light. Uniformity of weight and drug content, as per I. P was also determined. Friability was measured using electrolabfriabilator. Hardness tester was used to determine the hardness.

Table 2: Formulation chart for mini tablets compression and coating

\begin{tabular}{|c|c|c|c|c|c|}
\hline \multirow[t]{3}{*}{ S. No. } & \multirow[t]{3}{*}{ Ingredients } & \multicolumn{4}{|c|}{ Qty/Tab (mg) } \\
\hline & & \multicolumn{4}{|c|}{ Core Tablet } \\
\hline & & F1 & F2 & F3 & F4 \\
\hline 1 & Lenalidomide & 3.038 & 3.038 & 3.038 & 3.038 \\
\hline 2 & Avicel 200 & 0.700 & 0.700 & 0.700 & 0.700 \\
\hline 3 & Prosol SMCC 90 & 1.722 & 1.722 & 1.722 & 1.722 \\
\hline 4 & Crosscarmellose sodium & 0.360 & 0.360 & 0.360 & 0.360 \\
\hline 5 & Aerosil 200 & 0.060 & 0.060 & 0.060 & 0.060 \\
\hline 6 & Magnesium Stearate & 0.120 & 0.120 & 0.120 & 0.120 \\
\hline \multicolumn{2}{|c|}{ Total weight of core tablets (mg) } & 6.000 & 6.000 & 6.000 & 6.000 \\
\hline \multicolumn{2}{|c|}{ Seal Coating } & $5.00 \%$ & $5.00 \%$ & $3.50 \%$ & $3.50 \%$ \\
\hline 1 & Eudragit L 100 & 0.180 & 0.180 & 0.126 & 0.126 \\
\hline 2 & Triethyl citrate & 0.120 & 0.120 & 0.084 & 0.086 \\
\hline 3 & IPA & q. s. & q. $s$. & q. s. & q. s. \\
\hline \multicolumn{2}{|c|}{ Total weight of seal coated tablets (mg) } & 6.300 & 6.300 & 6.210 & 6.210 \\
\hline \multicolumn{2}{|c|}{ Enteric Coating } & $25 \%$ & $20 \%$ & $20 \%$ & $25 \%$ \\
\hline 1 & Eudragit L 30D55(Solid) & 0.742 & 0.594 & 0.585 & 0.731 \\
\hline 2 & Triethyl citrate & 0.742 & 0.594 & 0.585 & 0.731 \\
\hline 3 & Talc & 0.082 & 0.066 & 0.065 & 0.081 \\
\hline 4 & Dimethicon & 0.009 & 0.007 & 0.007 & 0.009 \\
\hline 5 & Purified Water & q. s. & q. s. & q. s. & q. $s$ \\
\hline \multicolumn{2}{|c|}{ Total weight of Enteric coated tablets (mg) } & 7.875 & 7.560 & 7.450 & 7.760 \\
\hline
\end{tabular}

\section{Weight variation}

Initially, 20 units of pellets were randomly selected which was weighed individually and the average was calculated. Weight variation was carried out by using digital balance [16]. The digital weighing balance model used to calculate weight variation is shimadzu (model no. BL 220H). The percentage deviation in weight was calculated by:

$$
\% \text { Deviation }=\frac{\text { Average weight }- \text { weight of tablet }}{\text { Average weight }} \times 100
$$

\section{Tablet thickness}

In this, 10 tablets were assessed for thickness by using an electronic vernier caliper, Mitutoyo, Japan.

\section{Hardness}

Monsanto hardness tester was employed to evaluate the hardness of randomly selected mini tablets [16].

\section{Disintegration}

The disintegration of the capsule was examined by electro lab disintegration tester (USP) ED-2AL for 15 min.

\section{Dissolution}

The apparatus used for dissolution is electro lab TDT USL. Lenalidomide has high solubility across the physiological $\mathrm{pH}$ range. For carrying out dissolution profiles studies of lenalidomide delayed-release capsule, USP apparatus II was employed at 100 rotations per min with $0.1 \mathrm{~N} \mathrm{HCl}$ for first two hours and later at $\mathrm{pH} 6.8$ phosphate buffer [17].

\section{Stability studies}

Stability studies were carried out by storage of tablets in containers inside thermolab S. S. 304 and analysed at regular intervals for different parameters like appearance, assay of API, determination of degradation products, dissolution time etc.; Stability studies were conducted at following conditions. Storage conditions: $40{ }^{\circ} \mathrm{C} \pm 2{ }^{\circ} \mathrm{C} / 75 \% \mathrm{RH} \pm 5 \% \mathrm{RH}$, $25^{\circ} \mathrm{C} \pm 2{ }^{\circ} \mathrm{C} / 60 \% \mathrm{RH} \pm 5 \% \mathrm{RH}$ for the period of 1 and $3 \mathrm{mo}$ [18].

\section{RESULTS AND DISCUSSION}

\section{Preformulation studies}

Drug-excipient compatibility studies were examined using FTIR. The following graph was obtained (fig. 1). The drug and excipient were found to be compatible. 


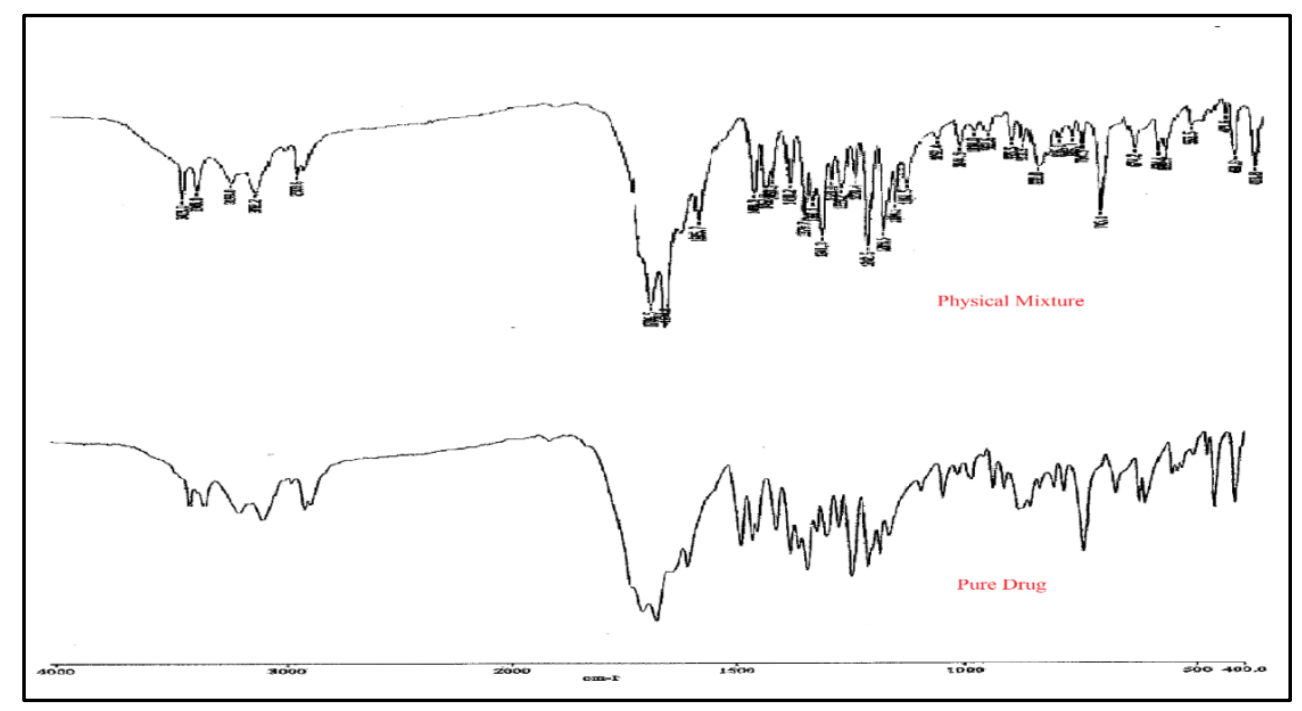

Fig. 1: FTIR of pure drug and physical mixture

\section{Post-compression and coating parameters}

Prepared tablets were evaluated during the process for weight variation, hardness, thickness, disintegration and tab letting issues such as capping, sticking, coating and results are tabulated in table 4 .

\section{Dissolution studies}

Dissolution studies were carried out by using $0.1 \mathrm{~N} \mathrm{HCl}$ buffer followed by $6.8 \mathrm{pH}$ buffer, and the results are depicted in table 5 .

The dissolution varied for all the formulation, the desired dissolution profile on comparison was achieved by formulation F4. The results obtained indicate that $\mathrm{F} 4$ meets all the in process parameters and hence, increased concentration of eudragit L30D55 of $25 \%$ has shown an increase in the drug release.

According to Umesh $N$ Et al. Mini particulate formulation coated with eudragit were targeted to release the drug in the intestine. A similar observation was made in the dissolution profile of the present study, wherein the drug showed no release in the acidic medium but exhibited 89.12-95.91\% release in the intestinal pH [19].

The comparative dissolution profile of the marketed product and lenalidomide DR capsule:

The Prepared lenalidomide DR capsules have shown more percentage of drug release than the available marketed formulation and the values are as shown in table 6 .

\section{Stability studies}

The stability studies for lenalidomidedelayed release mini tablets in capsules was carried out for optimized formulation. In accordance to ICH guidelines, stability studies were carried out by storing at $25{ }^{\circ} \mathrm{C} / 60 \% \mathrm{RH}$ and $40{ }^{\circ} \mathrm{C} / 75 \% \mathrm{RH}$ for 1 and $3 \mathrm{mo}$ was carried out for the optimized formulation. The samples were analysed and checked for changes in physical appearance and release profile at $1^{\text {st }}$ and $3^{\text {rd }}$ month, and the results are tabulated in table 7.

Table 4: Post-compression and coating parameters

\begin{tabular}{|c|c|c|c|c|c|c|c|c|}
\hline Formulations & F1 & & F2 & & F3 & & F4 & \\
\hline Test & CT & ECT & CT & ECT & CT & ECT & CT & ECT \\
\hline Average weight (mg) & $6.03 \pm 0.17$ & $7.88 \pm 0.11$ & $6.05 \pm 0.23$ & $7.5 \pm 0.12$ & $6.15 \pm 0.34$ & $7.42 \pm 0.15$ & $6.09 \pm 0.23$ & $7.74 \pm 0.11$ \\
\hline Hardness (N) & $18.5 \pm 0.25$ & $24.61 \pm 0.23$ & $17.18 \pm 0.42$ & $24.11 \pm 0.15$ & $19.53 \pm 0.38$ & $23.43 \pm 0.24$ & $19.33 \pm 0.21$ & $24.53 \pm 0.17$ \\
\hline Thickness (mm) & $1.85 \pm 0.09$ & $2.05 \pm 0.13$ & $1.83 \pm 0.21$ & $2.12 \pm 0.53$ & $1.79 \pm 0.28$ & $1.97 \pm 0.13$ & $1.85 \pm 0.17$ & $1.95 \pm 0.11$ \\
\hline $\begin{array}{l}\text { Disintegration (min) } \\
\text { at pH } 6.8 \text { buffer }\end{array}$ & - & 15 & - & 15 & - & $<15$ & - & $<10$ \\
\hline $\begin{array}{l}\text { Capping } \\
\text { Lamination and Sticking }\end{array}$ & Nil & Nil & Nil & Nil & Nil & Nil & Nil & Nil \\
\hline
\end{tabular}

mean $\pm \mathrm{SD}, n=3, \mathrm{CT}=$ Core tablet; $\mathrm{ECT}=$ Enteric Coated Tablet

Table 5: Dissolution profile of the drug

\begin{tabular}{|c|c|c|c|c|}
\hline \multirow{2}{*}{$\begin{array}{l}\text { Time (min) } \\
0.1 \mathrm{~N} \mathrm{Hcl} \mathrm{buffer}\end{array}$} & \multicolumn{4}{|l|}{ \% Drug release } \\
\hline & & & & \\
\hline Formulations & F1 & $\mathrm{F} 2$ & F3 & F4 \\
\hline $\begin{array}{l}120 \\
6.8 \mathrm{pH} \text { Phosphate buffer }\end{array}$ & $2.09 \pm 0.27$ & $1.25 \pm 0.44$ & $2.31 \pm 0.45$ & $1.02 \pm 0.37$ \\
\hline 5 & $44.32 \pm 0.37$ & $53.81 \pm 0.54$ & $54.32 \pm 0.48$ & $37.51 \pm 0.21$ \\
\hline 10 & $73.3 \pm 0.51$ & $83.7 \pm 0.24$ & $84.4 \pm 0.24$ & $93.21 \pm 0.24$ \\
\hline 15 & $89.12 \pm 0.24$ & $91.2 \pm 0.57$ & $93.4 \pm 0.28$ & $95.91 \pm 0.15$ \\
\hline
\end{tabular}

mean $\pm \mathrm{SD}, n=3$ 
Table 6: Comparative dissolution profile of the marketed product and lenalidomide DR capsule

\begin{tabular}{lll}
\hline Time (min) & \% Drug released of a marketed product & \% Drug released of lenalidomide capsule \\
\hline 0 & 0 & 0 \\
10 & $94.06 \pm 0.33$ & $93.21 \pm 0.24$ \\
15 & $95.21 \pm 0.18$ & $95.91 \pm 0.15$ \\
30 & $96.72 \pm 0.15$ & $97.2 \pm 0.31$ \\
45 & $97.5 \pm 0.52$ & $98.14 \pm 0.29$ \\
\hline
\end{tabular}

mean $\pm \mathrm{SD}, n=3$

Table 7: Stability studies

\begin{tabular}{|c|c|c|c|c|c|c|}
\hline $\begin{array}{l}\text { Condition and } \\
\text { month }\end{array}$ & Initial & $\begin{array}{l}25^{\circ} \mathrm{C} / 60 \% \text { RH (1- } \\
\mathrm{M})\end{array}$ & $\begin{array}{l}40{ }^{\circ} \mathrm{C} / 75 \% \mathrm{RH} \\
(1-\mathrm{M})\end{array}$ & $\begin{array}{l}25{ }^{\circ} \mathrm{C} / 60 \% \mathrm{RH} \\
(3-\mathrm{M})\end{array}$ & $\begin{array}{l}30{ }^{\circ} \mathrm{C} / 65 \% \mathrm{RH} \\
(3-\mathrm{M})\end{array}$ & $\begin{array}{l}40^{\circ} \mathrm{C} / 75 \% \mathrm{RH} \\
(3-\mathrm{M})\end{array}$ \\
\hline \multicolumn{7}{|l|}{ Dissolution $^{\mathrm{a}}$} \\
\hline Time preformed & \multicolumn{6}{|c|}{$\%$ Drug release } \\
\hline $\begin{array}{l}120 \min (0.1 \mathrm{~N} \\
\mathrm{HCl})\end{array}$ & $1 \pm 0.00$ & $1 \pm 0.00$ & $1 \pm 0.00$ & $1 \pm 0.00$ & $1 \pm 0.00$ & $1 \pm 0.00$ \\
\hline \multicolumn{7}{|c|}{ pH 6.8 Phosphate buffer } \\
\hline $10 \mathrm{~min}$ & $93.54 \pm 0.31$ & $95.13 \pm 0.47$ & $93.63 \pm 0.37$ & $94.32 \pm 0.19$ & $89.43 \pm 0.29$ & $89.12 \pm 0.21$ \\
\hline $15 \min$ & $94.42 \pm 0.53$ & $95.43 \pm 0.42$ & $95.65 \pm 0.54$ & $94.22 \pm 0.47$ & $94.29 \pm 0.39$ & $93.13 \pm 0.91$ \\
\hline $30 \mathrm{~min}$ & $95.91 \pm 0.54$ & $95.57 \pm 0.45$ & $95.31 \pm 0.29$ & $95.12 \pm 0.37$ & $94.42 \pm 0.37$ & $93.91 \pm 0.37$ \\
\hline $45 \mathrm{~min}$ & $97.42 \pm 0.42$ & $97.54 \pm 0.24$ & $97.82 \pm 0.65$ & $98.43 \pm 0.18$ & $95.21 \pm 0.82$ & $94.32 \pm 0.44$ \\
\hline
\end{tabular}

mean $\pm \mathrm{SD}, n=3$, There was no significant difference observed under $25^{\circ} \mathrm{C}$ and $60 \% \mathrm{RH}$ and $40{ }^{\circ} \mathrm{C}$ and $75 \% \mathrm{RH}$ accelerated stability condition at the end of $1^{\text {st }}$ and $3^{\text {rd }}$ month.

\section{CONCLUSION}

The delayed release of mini tablets in the capsule of lenalidomide was developed. The drug lenalidomide is found to have better in vitro drug release in mini-tablets form than the conventional dosage form. However, further clinical trials are necessary to ensure the improved efficacy and safety of lenalidomide mini tablets.

\section{AUTHORS CONTRIBUTIONS}

All the author have contributed equally

\section{CONFLICT OF INTERESTS}

Declared none

\section{REFERENCES}

1. Hadi MA, Rao NR, Rao AS. Formulation and evaluation of $\mathrm{pH}$ responsive mini-tablets for ileo-colonic targeted drug delivery. Trop J Pharm Res 2014;13:1021-9.

2. Mohd AH, Rao NG, Avanapu SR. Matrix-mini-tablets of lornoxicam for targeting early morning peak symptoms of rheumatoid arthritis. Iran J Basic Med Sci 2014;17:357.

3. Jeevana JB, Jyosna D. multi-particulate drug delivery systems using natural polymers as release retardant materials. Int J Pharm Pharm Sci 2010;6:61-5.

4. Ranjith K, Mahalaxmi R. Pharmaceutical mini tablets. Int J Pharmtech Res 2015;7:507-15.

5. Patel SA, Patel NG, Joshi AB. Multiple unit pellet system (mups) based fast disintegrating delayed-release tablets for pantoprazole delivery. Int J Pharm Pharm Sci 2010;10:77-84.

6. Murakami H, Kobayashi M, Takeuchi H, Kawashima Y. Utilization of poly (DL-lactide-co-glycolide) nanoparticles for the preparation of mini-depot tablets by direct compression. J Controlled Release 2000;67:29-36.

7. List AF, Baker AF, Green S, Bellamy W. Lenalidomide: targeted anemia therapy for myelodysplastic syndromes. Cancer Control 2006;13:4-11.

8. Jacob S, Shirwaikar AA, Joseph A, Srinivasan KK. Novel coprocessed excipients of mannitol and microcrystalline cellulose for preparing fast dissolving tablets of glipizide. Indian J Pharm Sci 2007;69:633.

9. Saettone MF, Chetoni P, Bianchi LM, Giannaccini B, Conte U, Sangalli ME. Controlled release of timolol maleate from coated ophthalmic mini-tablets prepared by compression. Int J Pharm 1995;126:79-82.

10. Kenneth N, Parthasarathy V, Narendra C, Kalyani P. Development and evaluation of oral controlled release matrix tablets of lamivudine optimization and in vitro-in vivo studies. Int J Pharm Pharm Sci 2015;7:95-101.

11. Vuong $H$, Palmer D, Levina $M$, Rajabi AR. Investigation of enteric coating of mini-tablets using a perforated pan or a fluid Bed machine. In: Poster Reprint Controlled Release Society Annual Meeting; 2008.

12. Li YH, Zhu JB. Modulation of combined-release behaviors from a novel "tablets-in-capsule system". J Controlled Release 2004;95:381-9.

13. Gasthuys F, Pockele K, Vervaet C, Weyenberg W, De Prijck K, Pille $\mathrm{F}$, et al. Evaluation of the in vivo behavior of gentamicin sulphate ocular mini-tablets in ponies. J Vet Pharmacol Ther 2007;30:470-6.

14. Rows RC, Sheskay PJ, Quinn ME. Handbook of pharmaceutical excipients. 6th ed. Pharmaceutical Press; 2009. p. 2018.

15. Hiorth M, Nilsen S, Tho I. Bioadhesive mini-tablets for vaginal drug delivery. Int J Pharm 2014;6:494-511.

16. Nair AB, Gupta R, Kumria R, Jacob S, Attimarad M. Formulation and evaluation of enteric coated tablets of proton pump inhibitor. J Basic Clin Pharm 2010;1:215.

17. De Brabander C, Vervaet C, Fiermans L, Remon JP. Matrix minitablets based on starch/microcrystalline wax mixtures. Int J Pharm 2000;199:195-203.

18. Keerthi ML, Kiran RS, Rao VU, Sannapu A, Dutt AG, Krishna KS Pharmaceutical mini-tablets, its advantages, formulation possibilities and general evaluation aspects: a review. Int J Pharm Sci Rev Res 2014;28:214-21.

19. Khatavkar U, Kumar K, Shimipi S. Novel approaches for the development of oral controlled release compositions of galantamine hydrobromide and paroxetine hydrochloride hemihydrate. Int J Appl Pharm 2016;8:1-6. 